\title{
The Effect of Sport Events Environments on Audience Attention to Advertising Using Brain Activity
}

\author{
1'Zahra Aminiroshan, ${ }^{1}$ Seyed Morteza Azimzadeh", ${ }^{1}$ Mahdi Talebpour, ${ }^{2}$ Majid Ghoshuni \\ ${ }^{1}$ Department of Sport Management, Faculty of Sport Science, Ferdowsi University of Mashhad, Mashhad, \\ Iran. ${ }^{2}$ Department of Biomedical Engineering, Mashhad Branch, Islamic Azad University, Mashhad, Iran.
}

Submitted 28 October 2019; Accepted in final form 21 December 2019.

\begin{abstract}
Background. Attention is considered as a resource for storing and processing memory activities. Without attention, no perceptual processing takes place in the brain as the information (whether visual or auditory) cannot enter the brain. Objectives. The purpose of this study was to investigate and compare the attention of individuals to sports and nonsports advertising using brain activities. Methods. It was a quasi-experimental study investigating two advertisements (sports and non-sports) of Apple Company on 30 volunteers (15 men and 15 women). The Neuroguide software was used to convert electroencephalographic data to quantitative data. Repeated measures ANOVA was used for testing hypotheses in SPSS software. Results. The results showed that there was a significant difference between watching sports and non-sports advertising on people's attention; in other words, sports advertising was able to reduce alpha in the frontal and pre-frontal brain while this decrease did not occur when viewing non-sports advertising. There was no significant difference in attention between men and women. Conclusion. Sport has the potential to attract people's attention, which is one of the main goals of companies and industry owners and can attract more attention in people to the advertised product, resulting in better brand retention and recall, and thus increasing promotional product or brand purchases.
\end{abstract}

KEYWORDS: Sport, Neuromarketing, Advertising, Attention, Electroencephalography.

\section{INTRODUCTION}

The content of the human mind is not under the full control of surrounding environmental stimuli at any moment, but it selects parts of the perceptual information available from the environment to process it more precisely and does not allow other information to enter the processing system; this active process of perceptual selection is called attention. Attention is one of the most important basic functions in the human brain whose components are the basis of other cognitive processes (1).

In today's world, many changes are happening with the expansion of competition in various fields, especially in markets. Marketing is essential for any kind of conscious move in today's market. A market that no longer recognizes specific boundaries or customers (2). For this reason, it is very important to use advertising as the most important marketing channel because it can stimulate customers (3). Advertising can drive customers to a new brand and increase market share, sales, and profits of the company as long as they can attract customer attention (4) as attracting customer attention is one of the biggest problems facing business owners and companies today (5).

In many models, attention has been cited as the first or one of the main factors influencing

*. Corresponding Author:

Seyed Morteza Azimzadeh, Assistant Professor

E-mail: mortezaazimzade@um.ac.ir 
advertising (6); the famous AIDA model introduced by Strong in 1925 may also be mentioned. The model is a behavioral model that includes four dimensions: attention, interest, desire, and action (7).

Applying this model to the advertising and sale processes is such that when a consumer sees the advertised product first, his or her attention is attracted to it, and, then, becomes interested in it, tend to buy goods and the advertised product (8). Wijaya BS later completed this model in 2012 (Figure 1) and introduced the upgraded model (9).

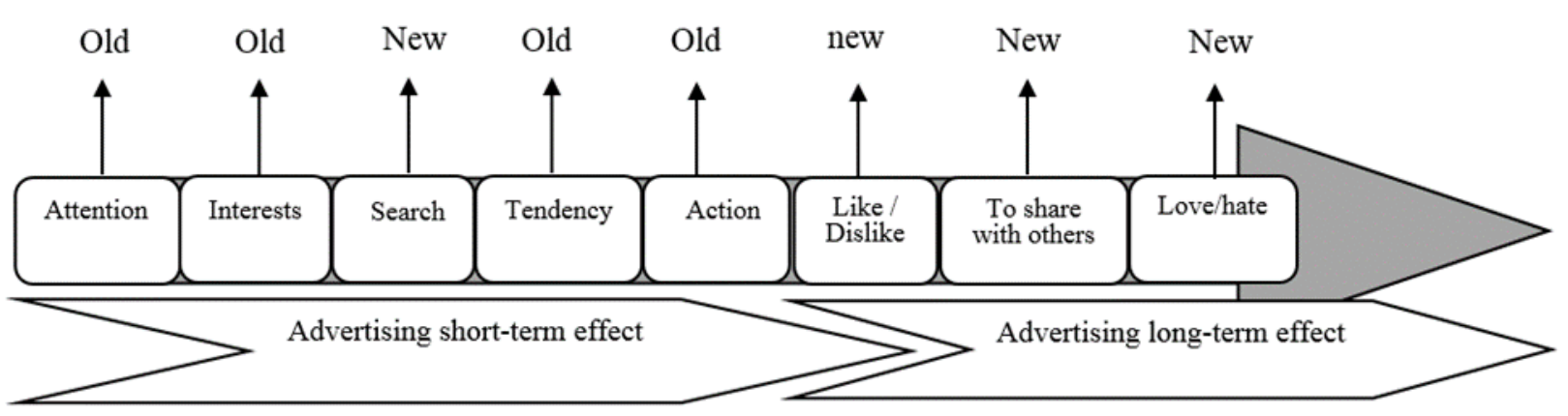

Figure 1. Upgraded AIDA model (Wijaya 2015)

According to researchers, customers who paid more attention to ads were also more likely to buy them, and brands whose ads didn't get people's attention were also less likely to sell (10-12). Attention to advertising leads to more brand appeal and more endurance in the minds of individuals (13-15), an issue that is the center of marketing goals and strategies of all companies. On the other hand, there is a direct relationship between visual attention and memory (13), and it is important to note that there is always a time gap between displaying advertising and buying a product, and when advertising is effective, it can attract people's attention. The promoted brand name stays in people's minds most and people remember it more easily when shopping $(14,16)$.

Worldwide, high costs are spent on advertising each year; global advertising spending for 2018 was $\$ 581$ billion, according to statistics from Statista, which was expected to grow four percent for 2019 compared to last year. (17). Statistics showed that in today's world, $80 \%$ of all new products introduced in the first three years fail (18); such companies ignore market developments and changing consumption patterns of customers, and instead of focusing on advanced marketing, they focus on sales (19). They try to find their audience only by speculation, which in today's highly competitive world does not seem to be a place for such speculation.

The researchers, therefore, sought to measure the success of advertising using neuromarketing techniques. Neuroscience abandons common practices and can start reading the mind of the customer directly, without the need for cognitive and conscious customer engagement (20). Customers' patterns of brain waves are closely related to their cognition and behavior (21), and there is, therefore, a marked increase in the use of brain-related techniques to analyze brain responses to commercial advertising or to examine the orientation of people's shopping trends (18, 22-25). Therefore, researchers are trying to investigate the symptoms of brain activity associated with increased attention, memory, and emotion involved while watching commercial advertising (26). By studying the research literature, we find that the power of alpha in the frontal and prefrontal part of the brain is correlated with the amount of attention the subject observes so that the increase of alpha band power in the frontal and prefrontal part decreases the attention and vice versa. The frontal and pre-frontal segments are associated with increased attention (27). In this regard, the results of the studies of Van Diepen et al. (2019), Moon et al. (2018), Berger and Davelaar (2018), Capotosto et al. (2009) can be mentioned; so that the results of all these studies confirmed this relationship and showed that the alpha power changes in the frontal and pre-frontal areas were directly correlated with changes in attention to the subject (27-30). Various studies also showed that individuals' attention to different colors depends on the alpha band power changes (31). In the field of advertising evaluation, many studies have 
confirmed this relationship and all have confirmed the association between decreased alpha-band activity in the frontal and pre-frontal brain with increased attention to advertising (32-34).

Simon et al. (2003), in a study that focused on people's attention to advertising and alpha bandwidth through EEG, reported that increased attention to observed advertising was significantly correlated with decreased alpha power (35). Vecciato et al. (2010), in a study on the amount of attention paid to brand advertising in both consumer and non-consumer groups, confirmed that decreasing alpha power in the frontal brain would lead to increased attention to advertising (34).

As mentioned, the issue of attention to advertising by audiences and consumers is a very important and influential factor, and on the other hand, people's attitudes towards public advertising have become more negative due to the repetition of advertising methods. As a result, finding the right advertising platform that can change people's attitudes toward advertising (positive) is highly felt (36); one of the areas that can be used to improve advertising attention is to use the sports environment. Sport has become the most important place to introduce and advertise products because of the great potential and positive economic benefits for many companies (37). Much research has been done in this regard, and many researchers have concluded that people's attitudes toward advertising through sport are positive $(38,39)$. In this regard, Kordlou's (2011) research can be mentioned, which stated that, unlike public advertising, respondents generally have a positive attitude to sports advertising and believe that sport's unique characteristics as an advertising medium affect the positive attitudes to advertising (36).

Bjelica (2014) also found that consumers' attitudes to advertising through sport were much more positive than normal (40). In a similar work, Muratovic (2014) assessed people's perceptions of sports and non-sports advertising and stated that sports-based advertising made people feel better and people viewed advertising better and more positively (41). Another research that can be mentioned in this regard is Masonovic research (2018). In a study examining the effect of sports advertising and its association with viewing sporting events, he concluded that not only sports advertising would be highly effective but also the impact of sports advertising on the group of people who watch sports events is higher (42). In general, sporting events provide tremendous opportunities for companies to introduce their brands and products through advertising (43) and because attention is one of the most important factors in the success of a company or brand, we are looking at whether sport alone can influence people's attention, and, more importantly, does sports advertising have more power to attract people's attention than non-sports advertising and has the potential to bring the benefits of the brand (retention and increased shopping) to the company? In this regard, there is a gap in the literature where sport and non-sport advertising were compared.

On the one hand, the private sector can be further encouraged to invest in different sectors of the sport, and on the other hand, with the increase in investment in sports, the reliance of sports federations and institutions on government resources can be changed so that they can achieve growth and excellence in sport, cause income generation and employment. This cannot be accomplished unless by studying and analyzing the complexity of the country's sports market with the help of researchers, experts, and experienced executives in the industry so they can develop the unique characteristics of the sport, including the sheer volume of cash flow, the tremendous potential for attracting employees and attracting funds.

\section{MATERIALS AND METHODS}

It was an applied quasi-experimental study and the data were collected in a laboratory.

Participants. The population of this study included students of the Ferdowsi University of Mashhad. The sample of the study was randomly selected from among the community members and consisted of 30 students of Ferdowsi University who participated in the research using an informed consent form. After clearing the recorded signals, the number of samples was 24 (13 males and 11 females) because the recorded signals of some individuals were noisy and could not be used. Subjects were between 20 and 35 years of age $(S D=3.77, \bar{x}=24.81)$. all righthanded, without any history of illness, drug and alcohol use, in healthy physical status, which was assessed using the General Health Questionnaire.

Instrument. Mitsar 21-channel electroencephalography device (202) was used to record the brain signal. The channels used in this study include the pair of electrodes F7, F8, F3, F4, Fp1, Fp2, and FZ which are in the frontal and prefrontal sections. The electrodes used in the device 
are $\mathrm{AgCl}$ electrodes inserted into the cap by the International 10-20 system. The reference electrodes were attached to the participants' ears, and the hardware filters arranged in the device were a $0.1 \mathrm{~Hz}$ cut-off filter and a $70 \mathrm{~Hz}$ cut-off filter.

Protocol Implementation. After selecting samples to record the signal, each person first looked at a 20-inch black screen (baseline) for one minute, followed by two one-minute ads on Apple brand products. The way the clips were shown to people was completely randomized to eliminate the effect of sequencing. Of these two advertisements, one introduced non-sports and the other sports ads. To better measure the effect of sport on people's attention, both ads were similar in terms of time, advertised product, and advertising display factors (such as image display quality, sound quality, resolution, etc.). The whole procedure was performed for all individuals only once, because, in the case of repetition, the clips were repeated for individuals and the attention factor could not be measured. The total protocol duration for each individual was approximately 3 minutes. It should be noted that all the above-mentioned steps have been carried out under the supervision of the Ethics Committee of Mashhad University of Medical Sciences.

Statistical Analysis. The data were initially analyzed using Neuroguide and SPSS 21 software and repeated measure ANOVA was used to test the research hypothesis.

\section{RESULT}

Initially, alpha power variations were calculated at the frontal and pre-frontal electrodes to account for changes in brain signals while viewing ads. In the next step, reduction or increase in these signals was observed, because, as discussed in the previous section, alpha power loss was considered in increased attention. For this purpose, the average alpha band power was calculated before viewing the $\mathrm{ad}$, during viewing the sport ad, and during viewing the non-sport ad (Table 1).

As can be seen in all channels, the alpha band power at rest (before viewing the ad) was higher than the other two modes, and in both (sport and non-sport) states, the alpha power decreased while watching the ad due to people's attention. However, the key issue is whether this decline was significant and whether sports advertising has attracted more attention? To use parametric or non-parametric statistics, the assumptions must first be examined. The first and most important statistical assumption was to determine the normality of the data distribution. For this purpose, the Kolmogorov-Smirnov test was used and all channels were normal in all three states.

Table 1. Average alpha power in different channels and modes

\begin{tabular}{|cccc}
\hline & Before watching the advertising & During watch sport advertising & During watch non-sport advertising \\
\hline channels & & & 5.35 \\
FP1 & 5.57 & 5.17 & 5.55 \\
FP2 & 5.84 & 5.39 & 5.56 \\
F3 & 6.51 & 5.40 & 6.17 \\
F4 & 7.22 & 5.97 & 5.35 \\
F7 & 4.59 & 3.92 & 5.55 \\
F8 & 4.96 & 4.43 & 6.47 \\
FZ & 7.6 & 6.35 & \\
\hline
\end{tabular}

Consequently, parametric statistical tests were used to investigate the assumptions, and repeated analysis of variance was used to test the research hypotheses and to investigate the difference of mean alpha band power before and during watching sports and non-sports advertising. Since the level of significance of the Muchley's test was less than $0.05(\mathrm{p}=0.000)$, the Sphericity Assumed test or the Greenhouse-Geisser test were used to test whether the hypothesis was significant or not. The results showed that the difference between Alpha Band power before and during watching sports and non-sport advertising was significant on most channels (Table 2).
What was of particular importance for the present study was to find out whether there was a difference between either sport or nonsport advertising with the time before advertising. For this reason, the Bonferroni post hoc test was used to determine the difference between the means, and it was observed that there was a significant difference between the baseline mode and the sports advertisement in most of the channels, whereas there was no significant difference between the baseline mode and the non-sport advertisement in any channels (Table 3 ). 
Table 2. Test of Between Subject Effects (Greenhouse-Geisser)

\begin{tabular}{cccccc}
\hline & $\begin{array}{c}\text { Type II Sum of } \\
\text { Squares }\end{array}$ & df & Mean Square & F & p \\
\hline Channels & & & & & \\
FP1 & 1.589 & 1.191 & 1.893 & 0.545 & 0.497 \\
FP2 & 2.129 & 1.178 & 2.509 & 0.596 & 0.473 \\
F3 & 13.051 & 1.316 & 17.172 & 4.921 & 0.025 \\
F4 & 18.460 & 1.164 & 21.491 & 4.518 & 0.038 \\
F7 & 15.423 & 1.596 & 24.611 & 8.460 & 0.002 \\
F8 & 9.218 & 1.650 & 15.211 & 3.727 & 0.041 \\
FZ & 17.970 & 1.296 & 23.295 & 4.298 & 0.038 \\
\hline
\end{tabular}

Table 3. Post Hoc test of different channels

\begin{tabular}{|c|c|c|c|c|c|}
\hline Factors & $\begin{array}{c}\text { Mean } \\
\text { Difference }\end{array}$ & $\begin{array}{c}\text { Std. } \\
\text { Error }\end{array}$ & $\mathbf{p}$ & $\begin{array}{l}\text { Lower Band }(95 \% \\
\text { CI) }\end{array}$ & $\begin{array}{l}\text { Upper Band }(95 \% \\
\text { CI) }\end{array}$ \\
\hline \multicolumn{6}{|l|}{ F3 channel before watch ad } \\
\hline F3 channel during watch sport ad & 1.107 & 0.432 & 0.017 & 0.214 & 2 \\
\hline $\begin{array}{l}\text { F3 channel during watch non- } \\
\text { sport ad }\end{array}$ & 0.946 & 0.457 & 0.051 & 0.002 & 1.891 \\
\hline \multicolumn{6}{|l|}{ F4 channel before watch ad } \\
\hline F4 channel during watch sport ad & 1.254 & 0.519 & 0.025 & 0.171 & 2.319 \\
\hline $\begin{array}{l}\text { F4 channel during watch non- } \\
\text { sport ad }\end{array}$ & 1.047 & 0.542 & 0.066 & -0.075 & 2.169 \\
\hline \multicolumn{6}{|l|}{ F7 channel before watch ad } \\
\hline F7 channel during watch sport ad & 0.668 & 0.302 & 0.037 & 0.430 & 1.293 \\
\hline $\begin{array}{l}\text { F7 channel during watch non- } \\
\text { sport ad }\end{array}$ & -0.763 & 0.427 & 0.087 & -1.646 & 0.120 \\
\hline \multicolumn{6}{|l|}{ F8 channel before watch ad } \\
\hline F8 channel during watch sport ad & .535 & .389 & .049 & .390 & 1.184 \\
\hline $\begin{array}{l}\text { F8 channel during watch non- } \\
\text { sport ad }\end{array}$ & -.590 & .495 & .246 & -1.615 & .434 \\
\hline \multicolumn{6}{|l|}{ FZ channel before watch ad } \\
\hline $\begin{array}{l}\text { FZ channel during watch sport } \\
\text { ad }\end{array}$ & 1.263 & 0.544 & 0.029 & 0.139 & 2.388 \\
\hline $\begin{array}{l}\text { FZ channel during watch non- } \\
\text { sport ad }\end{array}$ & 1.141 & 0.567 & 0.056 & -0.033 & 2.314 \\
\hline
\end{tabular}

Another hypothesis of the present study was that observing the ads of a non-sporting product through sport compared to non-sporting advertising of the same product had a significant difference between males and females, but, according to the results, this difference in the alpha band was not significant between males and females (Table 4).

Table 4. - Test of Between Subject Effects in Channels by Gender (Greenhouse-Geisser)

\begin{tabular}{cccccc}
\hline & $\begin{array}{c}\text { Type II Sum of } \\
\text { Squares }\end{array}$ & df & Mean Square & F & p \\
\hline Channels & & & & & \\
FP1 & 5.029 & 1.309 & 3.844 & 0.925 & 0.370 \\
FP2 & 9.934 & 1.728 & 5.749 & 2.603 & 0.094 \\
F3 & 6.063 & 1.658 & 3.656 & 2.193 & 0.134 \\
F4 & 6.515 & 1.168 & 5.578 & 1.393 & 0.254 \\
F7 & 1.790 & 1.322 & 1.354 & 0.502 & 0.535 \\
F8 & 11.965 & 1.204 & 8.264 & 2.349 & 0.050 \\
FZ & 10.947 & 1.231 & 7.519 & 2.254 & 0.051 \\
\hline
\end{tabular}

\section{DISCUSSION}

The relationship between the decrease in alpha band strength in the frontal and pre-frontal areas and the increase in visual attention has been established in many basic studies $(27-31,35)$. In the field of advertising evaluation, many studies have cited this relationship, and all have confirmed the association between decreased alpha-band activity in the frontal and pre-frontal brain with increased attention to advertising (32-34, 44). In this regard, we examined the issue of whether sport and watching of sports scenes can produce this 
alpha in comparison to non-sport ones. The results of the present study showed that the alpha band power was significantly different between the preobservation (resting) state and the sport mode in most of the channels, which means that the sports advertisement creates more attention for people watching sports ads by lowering alpha in the frontal and pre-frontal brain areas. However, there was no difference in any of the channels between pre-observation (resting) and non-sport mode. In contrast, non-sport advertisements produced higher alpha power in the frontal and pre-frontal segments of the brain, indicating that the nature of non-sport scenes creates less attention for people. The results of the present study are consistent with those of Zoric et al. (2018), Popovic et al. (2015), Bjelica et al. (2014), Muratovic (2014), Bennett (2006), Kordlou (2011), Behnam (2014) and Sajjadi (2007); so that all the results confirmed the conclusion that sport creates a positive tendency for the product and attracts attention in the individual (36, 40, 41, 45-49). According to the results of this study, sport can attract people's attention to the advertised product and thus can create benefit. The importance of this issue is further enhanced because the link between paying more attention to a subject or product and remembering it in marketing, designing, and producing products has been scientifically proven, and scientists show that lowering the alpha frontal due to causing greater attention in individuals makes the person love the advertised product and eventually buy it (10-12).

In this study, we also measured people's attention between sports and non-sports advertising between the two groups of men and women. The results showed that there was no significant difference between men and women when viewing ads (sports and non-sports) and the baseline mode because none of the ads were biased or genderspecific. However, research on gender content or bias for women or men has shown a significant difference between men and women, including Cartocci et al. (2016). He used machine advertising in his research and observed a significant difference between men and women (50).

The results of this study are in line with those of Yilmaz et al. (2014) (51). In this study, they examined the gender differences and spectral power of brain waves between participants and aimed at comparing the spectral power of brain waves between two groups of male or female participants. They concluded that the spectral power analysis was similar between male and female participants who liked the product. Wonderlich-Tierney (2013), in a study on foodrelated advertising and food intake, also found no significant difference between men's and men's brain activities in different modes (52).

\section{CONCLUSION}

Based on the findings of the present study, it can be argued that using sports content advertising will be very useful for the success of the company and the benefit of advertising because it can influence people's brain activities and increase the attention and ultimately the purchase of the advertised product. Therefore, all marketers and business owners use sports scenes and content to promote their products (non-sports and sports products) to attract the attention of consumers and thereby increase the likelihood of their products being purchased. Most importantly, this increase in attention is not specific to a particular group and is not gender-specific. One of the limitations of the present study was the absence of a device with more electrodes. The instrument used in this study was a 21-channel probe and we were unable to record the signal in some parts of the frontal and pre-frontal areas. It was also better to use an eye detector device to monitor eye movements.

\section{APPLICABLE REMARKS}

- Considering the expansion and specialization of studies in the field of sports marketing, a study can also examine and compare the impact of sport on the attention of different groups of society such as athletes, nonathletes, fans, non-fans.

- The other research can investigate the impact of age on attention to sports and non-sports advertising.

- Another study can investigate and compare the amount of attention paid to national sports advertising with international samples.

- Attention taking to sport ads should be compared using other neuromarketing tools such as ocular trackers, FMRIs, and so on.

- The impact of sports scenes and advertising on other factors influencing advertising success, such as being pleasant, retention in mind, rebranding, etc. should be carefully examined considering different bands' changes and comparing them to non-sports advertising. 


\section{REFERENCES}

1. Javadipour S, Ashayeri H, Kamali M, Akbar Fahimi M, Aliabadi F. Study of Visual Selective Attention Effect on Quality of Handwriting in 18-22 Years Old Students of Rehabilitation Sciences School of Iran Medical Sciences University. Middle Eastern Journal of Disability Studies. 2012;1(2):52-7.

2. Khodaparast S, Razavi SMH, Rezaee Soufi M, Safania AM. Designing and Preparing the Development Model of Marketing in Volleyball Super League of Iran. Annals of Applied Sport Science. 2019;7(4):18. doi: 10.29252/aassjournal.600

3. Sharifi M, Pool JK, Jalilvand MR, Tabaeeian RA, Jooybari MG. Forecasting of advertising effectiveness for renewable energy technologies: A neural network analysis. Technological Forecasting and Social Change. 2019; 143:154-61. doi: 10.1016/j.techfore.2019.04.009

4. Riebe E, Wright M, Stern P, Sharp B. How to grow a brand: Retain or acquire customers? Journal of Business Research. 2014;67(5):990-7. doi: 10.1016/j.jbusres.2013.08.005

5. Simmonds L, Bellman S, Kennedy R, Nenycz-Thiel M, Bogomolova S. Moderating effects of prior brand usage on visual attention to video advertising and recall: An eye-tracking investigation. Journal of Business Research. 2019. doi: 10.1016/j.jbusres.2019.02.062

6. Barry TE, Howard DJ. A review and critique of the hierarchy of effects in advertising. International Journal of Advertising. 1990;9(2):121-35. doi: 10.1080/02650487.1990.11107138

7. Hassan S, Nadzim SZA, Shiratuddin N. Strategic use of social media for small business based on the AIDA model. Procedia-Social and Behavioral Sciences. 2015; 172:262-9. doi: 10.1016/j.sbspro.2015.01.363

8. Chan L-Y, Su M-S, Huang C-M. Research on TV advertising effectiveness of the Taiwan Super Basketball League. International Journal of Organizational Innovation (Online). 2010;3(2):199.

9. Wijaya BS. The development of hierarchy of effects model in advertising. International Research Journal of Business Studies. 2015;5(1).

10. Bellman S, Nenycz-Thiel M, Kennedy R, Larguinat L, McColl B, Varan D. What Makes a Television Commercial Sell? Using Biometrics to Identify Successful Ads: Demonstrating Neuromeasures' Potential On 100 Mars Brand Ads with Single-Source Data. Journal of Advertising Research. 2017;57(1):53-66. doi: 10.2501/JAR-2016-051

11. Ehrenberg A, Barnard N, Kennedy R, Bloom H. Brand advertising as creative publicity. Journal of Advertising Research. 2002;42(4):7-18. doi: 10.2501/JAR-42-4-7-18

12. Percy L, Rossiter JR. A model of brand awareness and brand attitude advertising strategies. Psychology \& Marketing. 1992; 9(4): 263-274. doi: 10.1002/mar.4220090402

13. Pieters R, Wedel M, Zhang J. Optimal feature advertising design under competitive clutter. Management Science. 2007;53(11):1815-28. doi: 10.1287/mnsc.1070.0732

14. Vaughan K, Beal V, Romaniuk J. Can Brand Users Really Remember Advertising More Than Nonusers?: Testing an Empirical Generalization Across Six Advertising Awareness Measures. Journal of Advertising Research. 2016;56(3):311-20. doi: 10.2501/JAR-2016-037

15. Harrison F. Digging deeper down into the empirical generalization of brand recall: Adding owned and earned media to paid-media touchpoints. Journal of Advertising Research. 2013;53(2):181-5. doi: 10.2501/JAR-53-2-181-185

16. Rice B, Bennett R. The relationship between brand usage and advertising tracking measurements: International findings. Journal of Advertising Research. 1998;38(3):58-66.

17. Global advertising spending from 2014 to 2020 (in billion U.S. dollars). Available from: www.statista.com/statistics/273288/advertising-spending-worldwide/ [cited july 2018].

18. Calvert GA, Brammer MJ. Predicting consumer behavior: using novel mind-reading approaches. IEEE pulse. 2012;3(3):38-41. doi: 10.1109/MPUL.2012.2189167 pmid: 22678839

19. Seifpanahi Shabani J, Gharehkhani H, Naderi F. The Role of Sport Marketing Mix in Generating Revenue for Iranian Football Clubs. Annals of Applied Sport Science. 2018;6(1):95-102. DOI:10.29252/aassjournal.6.1.95

20. Sebastian V. Neuromarketing and evaluation of cognitive and emotional responses of consumers to marketing stimuli. Procedia-Social and Behavioral Sciences. 2014; 127:753-7. doi: 10.1016/j.sbspro.2014.03.349 
21. Ohme R, Matukin M. A small frog that makes a big difference: Brain wave testing of TV advertisements. IEEE pulse 2012; 3(3): 28-33. doi: 10.1109/MPUL.2012.2189169 pmid: 22678837

22. Ariely D, Berns GS. Neuromarketing: the hope and hype of neuroimaging in business. Nature reviews neuroscience. 2010;11(4):284. doi:10.1038/nrn2795 pmid: 20197790

23. Fischer NL, Peres R, Fiorani M. Frontal Alpha Asymmetry and Theta Oscillations Associated with Information Sharing Intention. Frontiers in behavioral neuroscience. 2018;12. doi: 10.3389/fnbeh.2018.00166 pmid: 30116183

24. Harmon-Jones E, Gable PA. On the role of asymmetric frontal cortical activity in approach and withdrawal motivation: An updated review of the evidence. Psychophysiology. 2018;55(1): e12879. dloi: 10.1111/psyp. 12879 pmid: 28459501

25. Harmon-Jones E, Gable PA, Peterson CK. The role of asymmetric frontal cortical activity in emotionrelated phenomena: A review and update. Biological psychology. 2010;84(3):451-62. doi: 10.1016/j.biopsycho.2009.08.010 pmid: 19733618

26. Jesulola E, Sharpley CF, Bitsika V, Agnew LL, Wilson P. Frontal alpha asymmetry as a pathway to behavioural withdrawal in depression: Research findings and issues. Behavioural Brain Research. 2015; 292:56-67. doi: 10.1016/j.bbr.2015.05.058 pmid: 26051816

27. Moon J, Kwon Y, Park J, Yoon WC. Detecting user attention to video segments using interval EEG features. Expert Systems with Applications. 2019; 115:578-92. doi: 10.1016/j.eswa.2018.08.016

28. Berger AM, Davelaar EJ. Frontal alpha oscillations and attentional control: a virtual reality neurofeedback study. Neuroscience. 2018; 378:189-97. doi: 10.1016/j.neuroscience.2017.06.007 pmid: 28642166

29. Capotosto P, Babiloni C, Romani GL, Corbetta M. Frontoparietal cortex controls spatial attention through modulation of anticipatory alpha rhythms. Journal of Neuroscience. 2009;29(18):5863-72. dloi: 10.1523/JNEUROSCI.0539-09.2009 pmid: 19420253

30. Van Diepen R, Foxe JJ, Mazaheri A. The functional role of alpha-band activity in attentional processing: The current zeitgeist and future outlook. Current opinion in psychology. 2019. doi: 10.1016/j.copsyc.2019.03.015 pmid: 31100655

31. Yoto A, Katsuura T, Iwanaga K, Shimomura Y. Effects of object color stimuli on human brain activities in perception and attention referred to EEG alpha band response. Journal of Physiological Anthropology. 2007;26(3):373-9. doi: 10.2114/jpa2.26.373 pmid: 17641457

32. Vecchiato G, Kong W, Giulio Maglione A, Wei D. Understanding the impact of TV commercials. IEEE pulse. 2012;3(3):42. doi: 10.1109/MPUL.2012.2189171 pmid: 22678840

33. Baraybar-Fernánde A, Baños-González M, Barquero-Pérez Ó, Goya-Esteban R, de-la-Morena-Gómez A. Evaluation of Emotional Responses to Television Advertising through Neuromarketing. Comunicar: Media Education Research Journal. 2017;25(52):19-28. doi: 10.3916/C52-2017-02

34. Vecchiato G, Astolfi L, Fallani FDV, Cincotti F, Mattia D, Salinari S, et al. Changes in brain activity during the observation of TV commercials by using EEG, GSR and HR measurements. Brain topography. 2010;23(2):165-79. doi: 10.1007/s10548-009-0127-0 pmid: 20033272

35. Simons RF, Detenber BH, Cuthbert BN, Schwartz DD, Reiss JE. Attention to television: Alpha power and its relationship to image motion and emotional content. Media psychology. 2003;5(3):283-301. doi: 10.1207/S1532785XMEP0503_03

36. Kordlu H, Elahi A, Khodayari A. The cause and effect relation between beliefs, attitude toward advertising through sport and attitude toward common advertising: the results of structural equations model. Sport Management Review. 2015; 30:203-24

37. Saberi A, Kalateh Seifari M, Dosti M, Razavi SMH, Farzan F. Designing a Sport Development Model in Iran's Free Trade Industrial Zones. Annals of Applied Sport Science. 2018;6(4): 49-58. doi: 10.29252/aassjournal.6.4.49

38. James JD. Attitude toward advertising through sport: A theoretical framework. Sport Management Review. 2011;14(1):33-41. doi: 10.1016/j.smr.2009.12.002

39. Pyun DY, James JD. Enhancing advertising communications: Developing a model of beliefs about advertising through sport. International Journal of Sport Communication. 2009;2(1):1-20. doi: 10.1123/ijsc.2.1.1 
40. Bjelica D, Popović S, Jakšić D, Hadžić R, Akpinar S, editors. How Does Advertising through Sport Work? Evidence from Turkey. 7th International Scientific Conference on Kinesiology; 2014.

41. Muratovic A, Bjelica D, Popovic S. Examining beliefs and attitudes toward advertising through sport among montenegrin consumers. Facta Universitatis, Series: Physical Education and Sport. 2014:95-104.

42. Masanovic B. Attitudes of consumers from Autonomous Province of Vojvodina toward advertising through sport in relation with the frequency of watching sports events. Sport Mont. 2018;16(3):91-6. doi: $10.26773 / \mathrm{smj} .181016$

43. Keshkar S, Lawrence I, Dodds M, Morris E, Mahoney T, Heisey K, et al. The Role of Culture in Sports Sponsorship: an Update. Ann Appl Sport Sci. 2019;7(1):57-81. doi: 10.29252/aassjournal.7.1.57

44. Tapia Frade A, Martín Guerra E, Puente JE. Neurociencia y publicidad. Atención, emoción y su relación con los premios obtenidos en el Festival Internacional de Publicidad de Cannes. Anàlisi: quaderns de comunicació i cultura. 2016:0075-95.

45. Behnam M, Gudarzi M, Hamidi M. The influence of advertising appeal on future intention and consumer's attitude toward advertisement in sport service. Sport Management Review. 2015(30):35-54.

46. Bennett G, Ferreira M, Tsuji Y, Siders R, Cianfrone B. Analysing the effects of advertising type and antecedents on attitude towards advertising in sport. International Journal of Sports Marketing and Sponsorship. 2006;8(1):56-75. doi: 10.1108/IJSMS-08-01-2006-B008

47. Popović S, Jakšić D, Matić R, Bjelica D, Maksimović N. Examining Beliefs and Attitudes toward Advertising through Sport among Serbian Consumers. Studia sportiva. 2015;9(1):225-31. doi: 10.5817/StS2015-1-28

48. Zorić G, Mašanović B, Gardašević J. Attitudes of Montenegrin consumers toward advertising through sport among the question how often consumers purchase sporting goods. Journal of Anthropology of Sport and Physical Education. 2018;2(1):21-5. doi: 10.26773/jaspe.180104

49. Sajjadi SN, Omidi A, Zare g. The relation between the use of sports in advertising and consumer behavior of sports spectator. Harekat. 2007; 34:83-93.

50. Cartocci G, Cherubino P, Rossi D, Modica E, Maglione AG, Di Flumeri G, et al. Gender and age-related effects while watching TV advertisements: an EEG study. Computational intelligence and neuroscience. 2016;201-206. doi: 10.1155/2016/3795325 pmid: 27313602

51. Yılmaz B, Korkmaz S, Arslan DB, Güngör E, Asyalı MH. Like/dislike analysis using EEG: determination of most discriminative channels and frequencies. Computer methods and programs in biomedicine. 2014;113(2):705-13. doi: 10.1016/j.cmpb.2013.11.010 pmid: 24326336

52. Wonderlich-Tierney AL, Wenzel KR, Vander Wal JS, Wang-Hall J. Food-related advertisements and food intake among adult men and women. Appetite. 2013; 71:57-62. doi: 10.1016/j.appet.2013.07.009 pmid: 23917064 